\title{
Hot-film and calorimetric thermal air flow sensors realized with printed board technology
}

\author{
Thomas Glatzl $^{1}$, Samir Cerimovic ${ }^{1}$, Harald Steiner ${ }^{1}$, Almir Talic ${ }^{1}$, Roman Beigelbeck ${ }^{1}$, \\ Artur Jachimowicz $^{2}$, Thilo Sauter ${ }^{1,3}$, and Franz Keplinger ${ }^{2}$ \\ ${ }^{1}$ Center for Integrated Sensor Systems, Danube University Krems, Wiener Neustadt, Austria \\ ${ }^{2}$ Institute of Sensor and Actuator Systems, TU Wien, Vienna, Austria \\ ${ }^{3}$ Institute of Computer Technology, TU Wien, Vienna, Austria \\ Correspondence to: Thomas Glatzl (thomas.glatzl@donau-uni.ac.at)
}

Received: 15 October 2015 - Revised: 13 May 2016 - Accepted: 15 June 2016 - Published: 19 July 2016

\begin{abstract}
This paper addresses the development of flow sensors optimized for heating, ventilating, and air conditioning systems. The sensors are based on the printed circuit board technology facilitating robust, flexible (in terms of layout), and cost-effective devices. Two approaches for measuring fluid quantities like flow velocity over the whole cross section are investigated in this context. The first one relies on hot-film transduction and stands out for its simplicity, but also shows some severe limitations, which can be circumvented by the second approach based on calorimetric transduction. Supported by extensive numerical simulations, several sensor embodiments were investigated and fabricated. After experimental characterization, measurement and simulation results were compared, which turned out to be in good agreement.
\end{abstract}

\section{Introduction}

The supply of today's urban agglomerations would not be possible without modern energy technology. Big residential and commercial buildings demand continuous power supply, where about $35 \%$ of their total energy use is consumed by air conditioning and heating units, the so-called HVAC (heating, ventilating, and air conditioning) systems. Two-thirds of this amount is attributable to private living space and one-third to service buildings (Perez-Lombard et al., 2008). In the private sector, significant improvements have been made in order to reduce the overall energy consumption, but actions still have to be taken in the service sector. Analyses have shown that up to $40 \%$ of the energy demand can be saved by optimizing the air ventilation and conditioning systems (Fitzner, 2008). In order to achieve this, the installation of a sufficient number of sensors and actuators is required to obtain a detailed insight into the thermal management of the building and in further consequence to enhance the HVAC system. Flow parameters like flow velocity, air rate, and flow direction are potential key parameters in the optimization of building automation and environmental monitoring.
If the focus is on robust, flexible (regarding design layout), and cost-effective sensors rather than high sensing accuracies, then manufacturing technologies capable of mass production have to be taken into account. Moreover, these technologies should only consist of a few and inexpensive process steps to keep the total costs of the system at a reasonable level. A printed circuit board (PCB) is such a technology which is commonly used in consumer electronics as well as in many medical, aerospace, and industrial applications. As a consequence, it is not surprising that this technology has become interesting for the production of various types of sensors (Prijic et al., 2015; Nojdelov and Nihtianov, 2009; Cruz et al., 2014).

Micromachined flow sensors have a large number of applications. They are used to measure wind, wall shear stress, viscosity, monitor gas in gas chromatography, and fluid flow in flow cytometry (Kuo et al., 2012; Nguyen, 1997; Makinwa and Huijsing, 2001; Loefdahl and Gad-el Hak, 1999; Ju et al., 2011; Yu et al., 2008; Kaanta et al., 2009; Chua and Pak, 2015; Nguyen et al., 2014; Cubukcu et al., 2014; Reyes Romero et al., 2013). Flow sensors can be classified either as thermal or non-thermal. The thermal designs seem to 
be most promising for low-cost devices because of the lack of moving parts or complex transducers. Micromachined thermal flow sensors can be subclassified regarding the basic principle in thermoresistive, termocapacitive, thermoelectric, thermoelectronic, pyroelectric, and frequency analog sensors (Grimes et al., 2006).

There are two basic concepts of thermoresistive sensors based on hot-wire or hot-film conversion and calorimetric flow transduction. The first ones operate by heat transfer from a heated element to the surrounding fluid. This method needs one resistor which acts as heater and transducer at the same time, and, in some cases, a second resistor as sensor for the ambient temperature. This technology is known to be very sensitive regarding the flow velocity (Kohl et al., 2003). However, several drawbacks are the fragile design and the relatively expensive technology. To compensate for these drawbacks, attempts with thin flexible PCB carriers (Zhu et al., 2009; Que et al., 2011) and thin-film technology on flexible PCB substrates (Zhu et al., 2009; Que et al., 2011) were made. By contrast, the calorimetric principle requires additional temperature sensors upstream and downstream of the heater. The work presented in this paper employs a modified version of the calorimetric operation. The sensor is based on standard flexible PCB technology only and is optimized for the use in HVAC systems (Glatzl et al., 2014). Previous works established the concept of such PCB thermal sensors and discussed advantages and disadvantages (Glatzl et al., 2013; Sauter et al., 2014). In detail, this work is an extension of a conference paper and presentation (Glatzl et al., 2015) with additional material and new results.

\section{Sensor designs}

\subsection{Hot-film approach}

The first approach is based on hot-film anemometry (Saremi et al., 2014; Kuo et al., 2012) where the convective cooling of a passing fluid changes the temperature of a heating film and, consequentially, its electrical resistance. This resistance change can be exploited to acquire information about the fluid velocity. Hot-wire and hot-film anemometers are typically operated in two different modes (Cerimovic et al., 2013). In the first mode, the heater is supplied either with a constant current (CCA - Constant Current Anemometry) or a constant voltage (CVA - Constant Voltage Anemometry). The flow-dependent resistance change of the heater is detected by measuring the heater voltage or the probe current, respectively. In the second operating mode, a constant temperature difference between the probe and the ambient is established by means of an electronic controller (CTA constant temperature anemometry). The voltage or current required to maintain the constant excess temperature can be used as an output quantity for the flow velocity. Figure 1 shows a PCB-based hot-film sensor where the sensor embodiment features a meandering pattern with four strips. The

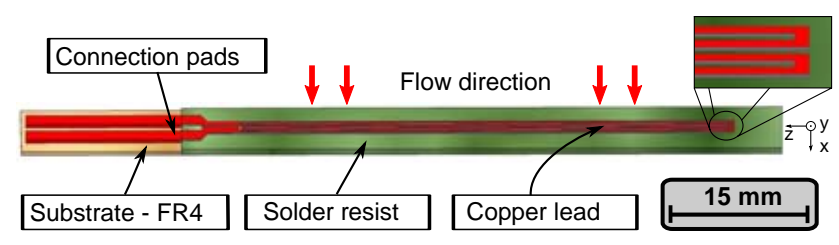

Figure 1. Hot-film anemometer produced on a PCB with a $100 \mu \mathrm{m}$ thick substrate (beige). The thickness of the copper leads (red) and of the solder resist (green - covers the copper leads except the connection pads) amounts to 5 and $40 \mu \mathrm{m}$, respectively.

strip width as well as the distance between adjacent strips amounts to $100 \mu \mathrm{m}$, while the length of the sensor meander is $5 \mathrm{~cm}$ (the complete length of the copper trace is roughly twice this length). The fabrication of the device started from a flexible standard FR4 epoxy glass substrate $(100 \mu \mathrm{m}$ thickness) laminated with a copper layer of a thickness of $18 \mu \mathrm{m}$ which was then narrowed down to $5 \mu \mathrm{m}$ by means of wet etching. Finally, the PCB was protected with a solder resist with a thickness of $40 \mu \mathrm{m}$. In hot-film operation, this copper layer serves simultaneously as a heating and temperature sensing element.

\subsection{Calorimetric approach}

Due to drawbacks (Sect. 5.1), the hot-film approach is not usable for HVAC systems. Therefore, a new PCB-based sensor design is proposed, which relies on the calorimetric transduction principle. The applied calorimetric method consists of a heating element and four spatially separated temperature sensing elements. The latter are symmetrically placed upstream and downstream of the heater, enabling flow direction detection. Figure 2 shows a sketch of the new sensor layout. The heater design (red) was adopted from the hot-film transducer. To determine the temperature at the upstream and downstream sites of the heater, four additional copper leads (blue and purple) were laminated on the substrate. In contrast to the heater, they consist only of two strips. Hence, its $R_{20}$ amounts to $3.82 \Omega$. The overall PCB width of the new design amounts to $2.5 \mathrm{~mm}$, whereas the sensor meander length remains the same. The basic application idea is to mount the sensor across the diameter of the pipe and thus measure an average velocity over the flow profile. Hence the length of the sensor investigated in this paper matches the size of the pipe used in the experiments.

PCBs with different layout variations (details in Fig. 2) have been produced, in order to improve the characteristics of the sensor in HAVC systems. The first change is a variation of the gap between the copper leads. For some sensor embodiments this gap has been increased from initially 100 to $200 \mu \mathrm{m}$ or even $300 \mu \mathrm{m}$. The second change includes perforations in the form of drilled holes in the gap between the copper leads. This adjustment decreases the spurious heat conduction through the substrate influencing the performance 
Table 1. Overview of the different sensor embodiments and the varied parameters.

\begin{tabular}{lrrrrrrrrr}
\hline Embodiment number & 1 & 2 & 3 & 4 & 5 & 6 & 7 & 8 & 9 \\
\hline Gap between the leads in $\mu \mathrm{m}(g)$ & 100 & 200 & 300 & 300 & 300 & 300 & 300 & 300 & 300 \\
\hline Hole diameter in $\mu \mathrm{m}\left(h_{\mathrm{d}}\right)$ & None & None & None & 100 & 100 & None & 100 & None & 100 \\
\hline Hole spacing in $\mu \mathrm{m}\left(h_{\mathrm{g}}\right)$ & None & None & None & 300 & 100 & None & 300 & None & 300 \\
\hline Wing width in $\mathrm{mm}(w)$ & 0.2 & 0.2 & 0.2 & 0.2 & 0.2 & 4.2 & 4.2 & 8.86 & 8.86 \\
\hline
\end{tabular}

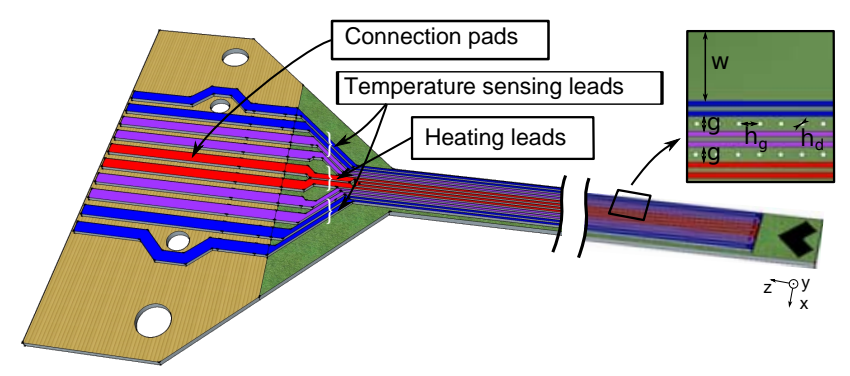

Figure 2. Schematic of the calorimetric transducer layout: the length of the meander is $50 \mathrm{~mm}$ and the overall thickness is about $140 \mu \mathrm{m}(100 \mu \mathrm{m}$ substrate and $40 \mu \mathrm{m}$ solder resist). Copper layers $5 \mu \mathrm{m}$ thick are embedded in the solder resist. The heating leads are red, the sensing ones are blue and purple, the solder resist is green and the substrate is yellow. At the left of the transducer are connection pads for soldering or a plug. Also, a detail of the transducer part gives an overview of the varied parameters: $g$ is the gap between the leads, $h_{\mathrm{d}}$ is the hole diameter, $h_{\mathrm{g}}$ is the hole spacing, and $w$ is the wing width.

of the sensor. In one version the hole diameter is $100 \mu \mathrm{m}$ with $100 \mu \mathrm{m}$ spacing between the holes. Another version features $300 \mu \mathrm{m}$ hole spacing. The last modification is the variation of the wing width. The wing width is the distance between the outer sensing lead and the edge of the sensor. This will strengthen the PCB stripe against fluttering as well as the thermal boundary layer over the heater. The initial wing width is only $0.2 \mathrm{~mm}$; other designs feature 4.2 and $8.86 \mathrm{~mm}$. These various parameters are limited by the sensor layout. Table 1 shows an overview of the varied parameters of the different designs.

\section{FEM simulation}

A 2-D-FEM model of the sensor was developed, in order to predict the behaviour of the transducer and to optimize the layout. Since all sensor components (the thermistors and the heater) exhibit a large extension perpendicular to the flow direction, two-dimensional modelling is reasonable, although the heating profile is not physically correct, because at the tip and the end of the sensor in the pipe there will be nearly no flow. However, 3-D-FEM simulations had been carried out to investigate the flow conditions in the pipe. The results of the
3-D simulation are implemented in the 2-D-FEM simulations via a small correction coefficient.

The Comsol Multiphysics simulation tool was applied for the simulation. The model is based on the cross-sectional view depicted in Fig. 3a). The sensor is placed in the center of the flow channel (corresponding to the experimental PMMApipe arrangement). The conjugated heat transfer module of Comsol Multiphysics combines heat transfer and fluid dynamics. A parabolic flow velocity profile was imposed at the flow inlet (Fig. 3b) and the non-slip boundary condition was applied to all surfaces (i.e. channel walls and sensor surface). The software package solves the incompressible Navier-Stokes equation in order to get the velocity field inside the channel and around the sensor (indicated with red arrows). Subsequently, the heat transfer equation incorporating conductive and convective heat transfer is solved. The boundary conditions for this mode at the inlet and outlet of the flow channel are implemented as convective flux, while the remaining parts of the model circumference were kept at a constant ambient temperature $\left(T_{\mathrm{amb}}=22^{\circ} \mathrm{C}\right)$. This is also the initial temperature value for all domains.

\section{Experimental set-up}

The experimental set-up is illustrated in Fig. 4. A PMMA pipe with a total length of $82 \mathrm{~cm}$ and an inner diameter of $d=5 \mathrm{~cm}$ was used as a flow channel. A fan (AVC double vane van, $12 \mathrm{~V}, 1.14 \mathrm{~A}$ ) was mounted at the one end of the pipe in order to establish a constant and well-defined air flow. A PC-controlled power supply regulates the voltage of the fan and thereby sets the flow velocity in the channel. Average flow velocities in the range of $0.6-3.66 \mathrm{~m} \mathrm{~s}^{-1}$ are achievable with the chosen fan type. The sensor was placed in the middle of the pipe and the voltage across the heater has been measured with a 6.5 digit voltage multimeter (Agilent 34410A/11A) controlled via a PC. A hundred measurement points were recorded for each flow velocity value and the resulting mean was used to plot the sensor output characteristic. The measurement uncertainty of the DVM was below $100 \mu \mathrm{V}$, whereas the standard variation of the experimental data was of the order of $2-3 \mathrm{mV}$ for all measurements. The standard deviation was thus too small to be depicted in the plots. 
(a)

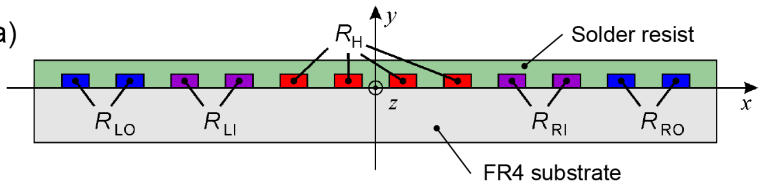

(b)

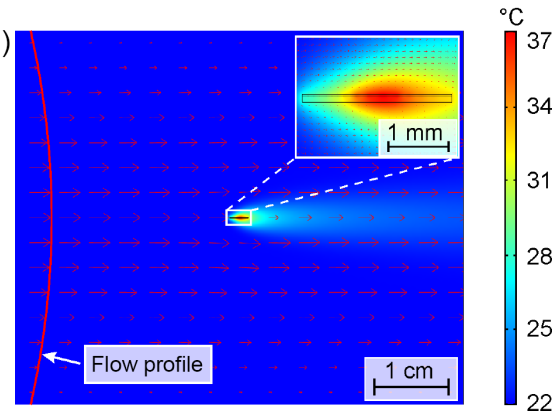

Figure 3. (a) FEM model cross section of the calorimetric flow sensor. Grey is the FR4 substrate, green the solder resist, red the heater leads $\left(R_{\mathrm{H}}\right)$, and blue and purple the sensing leads. The indexes indicate the position on the PCB: L/R means left/right to the hater, and O/I means outer/inner thermistor. (b) Result of the FEM simulation for a constant heating current of $I_{\mathrm{H}}=115 \mathrm{~mA}$. The red arrow indicates the velocity field at an average flow velocity of $v=0.1 \mathrm{~m} \mathrm{~s}^{-1}$.

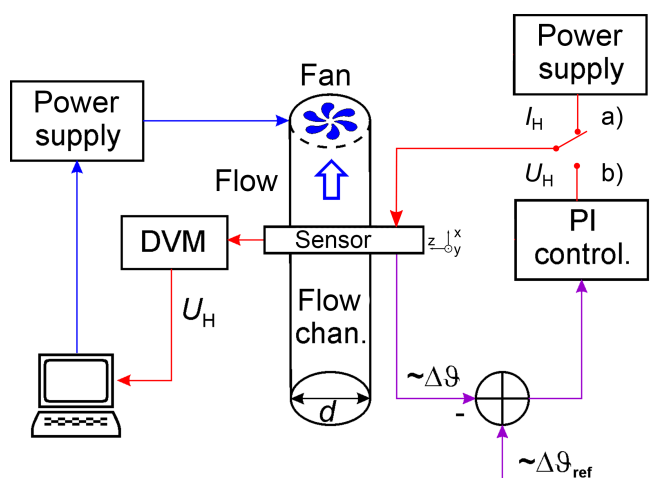

Figure 4. Sketch of the experimental set-up. The sensor was placed in the middle of the flow channel. An air flow was induced with a fan and the heater voltage has been measured with a digital voltage multimeter (DVM). The first sensor layout was supplied by a constant current $I_{\mathrm{H}}$ (a). For the second layout the heater voltage $U_{\mathrm{H}}$ was adjusted by a common PI controller in order to keep the difference between the mean temperature around the heater and the mean temperature at the sensor edges constant $\Delta \vartheta=\Delta \vartheta_{\text {ref }}(\mathbf{b})$.

\section{Results}

\subsection{Hot-film approach}

Before the actual measurements in the flow channel can be conducted, the copper layer has to be characterized. In order to evaluate the thermal thin-film properties, the PCB device was placed in a temperature chamber which was heated up and then turned off. During the cooldown phase, the resistance of the thin film was measured multiple times using a four-wire measurement approach. To avoid the influence of contact resistance, the probe wires were soldered to the sensor leads. In order not to have to rely on the inaccurate builtin sensor, the chamber temperature was measured with a conventional PT100 sensor (accuracy better than $0.2^{\circ} \mathrm{C}$ ) placed close to the device under test. Proper thermal coupling was ensured by forced convection inside the chamber using the

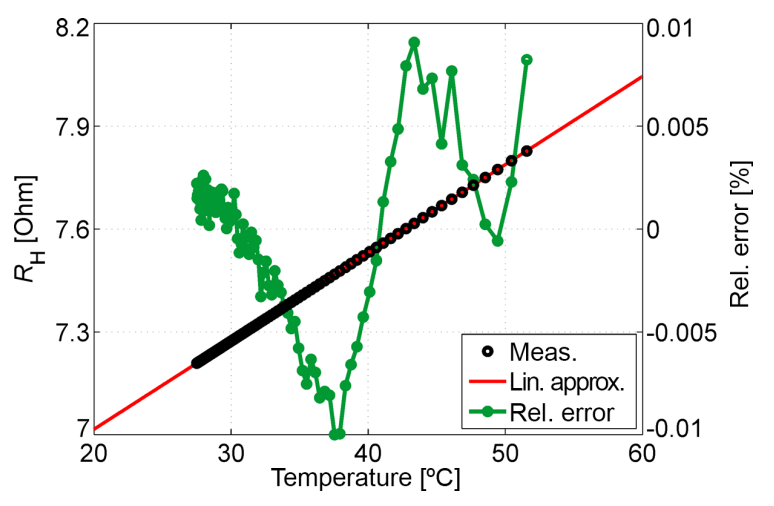

Figure 5. The measured heater resistance $R_{\mathrm{H}}$ of the copper lead (black circles) vs. temperature as well as the corresponding linear approximation (red) applied to deduce TCR and $R_{20}$. The green curve depicts the relative error of the linear approximation.

built-in fan (Fig. 5). The temperature-resistance equation for the copper layer reads as

$R=R_{20} \cdot(1+\alpha \cdot \Delta \vartheta)$,

where $\Delta \vartheta=\vartheta-20^{\circ} \mathrm{C}$ and $\vartheta$ are excess temperature and the absolute layer temperature, respectively. $R_{20}$ denotes the resistance in $\mathrm{Ohm}$ at $20^{\circ} \mathrm{C}$ and $\alpha$ is the first-order temperature coefficient of resistance (TCR). By applying Eq. (1) to the measured data, the two important parameters $R_{20}=7.02 \Omega$ and $\alpha=3.66 \times 10^{-3} 1 / \mathrm{K}$ can be calculated. The deduced TCR is in accordance with the values found in the literature (Leonard and Yu, 1973). Basically, the TCR is temperature dependent itself, which will impact the accuracy of the temperature measurement when the ambient temperature changes. However, Fig. 5 also shows that for the typical temperature range to be expected in HVAC systems, the linearity assumption is justified, and that this second-order effect will be small.

The thin-film heater was supplied with a constant heating current of $I_{\mathrm{H}}=115 \mathrm{~mA}$ which corresponds to a heating 


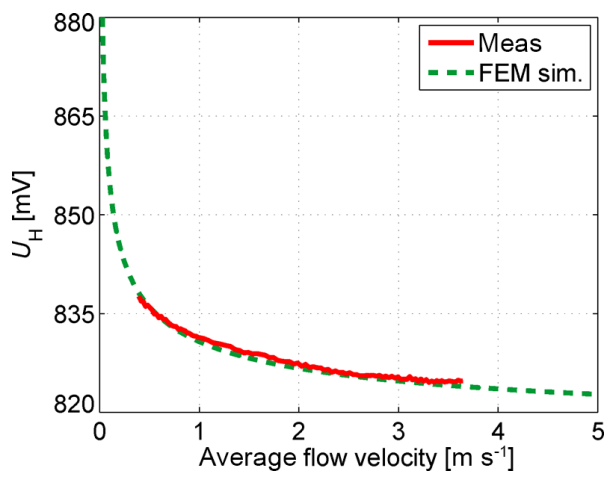

Figure 6. Voltage of the heater $U_{\mathrm{H}}$ as a function of the average flow velocity in the channel. The measured results are compared with FEM simulation results.

power of about $100 \mathrm{~mW}$ (Fig. 4a). The cooling air flow decreases the heater resistance. Since the heating current is imposed, the voltage across the heater follows this trend. In Fig. 6 the heater voltage ( $U_{\mathrm{H}}$, red curve) is plotted over the average flow velocity in the pipe and compared to the results (green curve) of the FEM (finite element method). Three major drawbacks of the hot-film sensor can be found by analysing the output characteristic. The first one is the saturation of the output signal. The aim of the described design was to measure velocities up to $10 \mathrm{~m} \mathrm{~s}^{-1}$. However, according to Fig. 6, the sensitivity (slope of the output characteristic) above $3 \mathrm{~m} \mathrm{~s}^{-1}$ is barely sufficient to detect the flow velocities properly. The second one is the direction independence, i.e. the output characteristic is an even function and, therefore, not dependent on the direction of the flow. However, for some applications the detection of flow direction is desirable. The third one is the ambient temperature dependence of the output characteristic imposed by temperature characteristics of the cooper thin layer. Consequently, the ambient temperature has to be measured too in order to compensate for this effect.

Figure 3 shows the simulated spatial temperature distribution $T$ at an average flow velocity of $v=0.1 \mathrm{~m} \mathrm{~s}^{-1}$ and a heater current of $I_{\mathrm{H}}=115 \mathrm{~mA}$. First, only the hot-film sensor was simulated, i.e. the thermistors left and right from the heater were omitted. A constant heating power was imposed at the heater corresponding to the heating with a constant current of $I_{\mathrm{H}}=115 \mathrm{~mA}$ like in the measurements. The simulation and measurements results are compared in Fig. 6. A very good agreement between simulation and measurement proves the feasibility of the 2-D-FEM approach.

\subsection{Calorimetric approach}

For the simulation of the calorimetric approach, the thermistors were also taken into account (Fig. 3). They were supplied with a constant current of $I_{0}=10 \mathrm{~mA}$, in order to keep their self-heating low. The excess temperatures $T$ at the ther- mistor sites were calculated by integrating the temperature $T$ over the thermistor area. Applying Eq. (1), the electrical resistances, and, hence, the voltages across each thermistor can be calculated $\left(U_{\mathrm{RO}}, U_{\mathrm{RI}}, U_{\mathrm{LI}}, U_{\mathrm{LO}}\right.$, where the indexes indicate the position on the PCB: L/R means left/right of the heater; $\mathrm{O} / \mathrm{I}$ means outer/inner thermistor). Finally, three relevant voltages were deduced.

1. Sum of the left side thermistor voltages minus the sum of the right side:

$$
\begin{array}{ccc}
U_{1} & = & \left(U_{\mathrm{RO}}+U_{\mathrm{RI}}\right)-\left(U_{\mathrm{LI}}+U_{\mathrm{LO}}\right) \\
& \propto & \left(T_{\mathrm{RO}}+T_{\mathrm{RI}}\right)-\left(T_{\mathrm{LI}}+T_{\mathrm{LO}}\right) \\
& \propto & T_{\mathrm{R}, \text { mean }}-T_{\mathrm{L}, \text { mean }},
\end{array}
$$

where $T_{\mathrm{R} \text {,mean }}$ and $T_{\mathrm{L} \text {, mean }}$ denote the mean temperature of the right and left parts of the sensor regarding the heater, respectively. The sign of this output can be used to detect the flow direction.

2. Sum of the inner thermistor voltages minus the sum of the outer thermistor voltages:

$$
\begin{array}{ccc}
U_{2} & = & \left(U_{\mathrm{LI}}+U_{\mathrm{RI}}\right)-\left(U_{\mathrm{LO}}+U_{\mathrm{RO}}\right) \\
& \propto & \left(T_{\mathrm{LI}}+T_{\mathrm{RI}}\right)-\left(T_{\mathrm{LO}}+T_{\mathrm{RO}}\right) \\
& \propto & T_{\mathrm{I}, \text { mean }}-T_{\mathrm{O}, \text { mean }},
\end{array}
$$

where $T_{\mathrm{I} \text {,mean }}$ and $T_{\mathrm{O} \text {,mean }}$ denote the mean temperature of the inner and outer parts of the sensor, respectively. This signal describes the difference between the mean temperature in the middle of PCB (measured by the inner thermistors) and the mean temperature at the periphery of the PCB (measured by the outer thermistors).

3. Sum of all thermistor voltages:

$$
\begin{array}{ccc}
U_{3} & \propto & U_{\mathrm{LO}}+U_{\mathrm{LI}}+U_{\mathrm{RI}}+U_{\mathrm{RO}} \\
& \propto & T_{\mathrm{LO}}+T_{\mathrm{LI}}+T_{\mathrm{RI}}+T_{\mathrm{RO}} \\
\propto & T_{\mathrm{S}, \text { mean }},
\end{array}
$$

where $T_{\mathrm{S} \text {, mean }}$ denotes the mean temperature of the whole PCB. This signal describes the cooling of the PCB and features the same trend as the $U_{\mathrm{H}}$ characteristic in Fig. 6. The main disadvantage of the CCA mode is the saturation of the output characteristic at higher flow velocities (Fig. 6). For a constant heating power of $100 \mathrm{~mW}$ and $v>3 \mathrm{~m} \mathrm{~s}^{-1}$, the convective cooling is so efficient that the difference between the hot-film temperature and the fluid temperature tends to zero, resulting in the saturation of the output signal. To overcome the saturation, the heating power at higher flow velocity must be increased. This operating mode can be achieved by electronically controlling the heater voltage and thus the heating power in order to keep the temperature difference between the sensor and the fluid at a constant level (CT constant temperature mode of the calorimetric flow sensor) (Kohl et al., 2003). The mean sensor temperature can be obtained from the voltage $U_{3}$ (Eq. 4), whereas the ambient fluid 
temperature must be measured by an external temperature sensor. Hence, a compact flow sensor based solely on PCB technology cannot be used in such a measurement configuration. Therefore, we propose to control the voltage $U_{2}$ (Eq. 3). Keeping this voltage constant by an electronic controller results in a constant difference between the mean temperatures of the inner and outer parts of the sensor $T_{\mathrm{I} \text {,mean }}-T_{\mathrm{O} \text {, mean }}=$ const. The temperature at the upstream edge of the sensor (measured by $R_{\mathrm{LO}}$, assuming a flow from the left side in Fig. 3a) is near the fluid temperature, whereas the temperature at the opposite downstream edge $R_{\mathrm{RO}}$ is much higher due to the convective heat transport from the heater. Thus, the mean temperature at the sensor edge $T_{\mathrm{O} \text {,mean }}$ differs from the fluid temperature. Nevertheless, the increase in the heater voltage in this quasi CT mode turned out to be sufficient enough for precise measurements in higher velocity ranges. This behaviour was established by FEM simulations. A temperature difference of $T_{\mathrm{I}, \text { mean }}-T_{\mathrm{O} \text {, mean }}=4 \mathrm{~K}$ was chosen in the simulation and the heater voltage was adjusted until this difference was reached. Moreover, assuming a $10 \mathrm{~mA}$ supply current for all temperature leads, the voltage across the thermistors is evaluated in order to calculate $U_{1}$ and $U_{2}$. The results gained from this simulation are depicted in Fig. 7. The required heater voltage $U_{\mathrm{H}}$ to keep the voltage $U_{2}$ at a constant level (corresponding to $T_{\mathrm{I}, \text { mean }}-T_{\mathrm{O} \text {, mean }}=4 \mathrm{~K}$ ) as well as the resulting voltage $U_{1}$ are plotted as a function of the average flow velocity. A signal saturation occurs for $U_{\mathrm{H}}$ above $15 \mathrm{~m} \mathrm{~s}^{-1}$ for airflow in the described simulation setup, which is sufficient for use in HVAC systems. Moreover, as the controller keeps the temperature difference (rather than the absolute value of the temperature) constant, variations of the fluid temperature have no influence on the output signal. $U_{1}$ features a high initial sensitivity (slope of the characteristic), reaches its maximal value around $7 \mathrm{~m} \mathrm{~s}^{-1}$ and decreases for higher flow velocities. Therefore, it can only be used for a low flow range of $v<0.5 \mathrm{~m} \mathrm{~s}^{-1}$, where the sensitivity is sufficient enough for flow velocity measurements. Nevertheless, the voltage $U_{1}$ can be used to detect the direction of the flow, since its sign is flow dependent.

To establish the quasi-CT operation mode, a common PI controller was applied (Fig. 4b). Figure 8 compares simulation results and experimental data for the calorimetric design and shows that the quasi-CT mode actually works. The measurement range for this set of experiments was limited from about 0.6 to $3.66 \mathrm{~m} \mathrm{~s}^{-1}$. Each sensor embodiment listed in Table 1 has been measured under the same condition in order to compare the different design variations. Due to the asymmetries and production tolerances, the individual offset voltage at zero flow $U_{\mathrm{H}}(0)$ differs from sensor to sensor. Hence, to enable realistic comparison, the offset-free heater voltage was used as a sensor output:

$U_{H, 0}(v)=U_{\mathrm{H}}(v)-U_{\mathrm{H}}(0)$.

The individual offset voltages are in the range from 0.9 to $1.3 \mathrm{~V}$. Figure 9 shows the output characteristic for three dif-

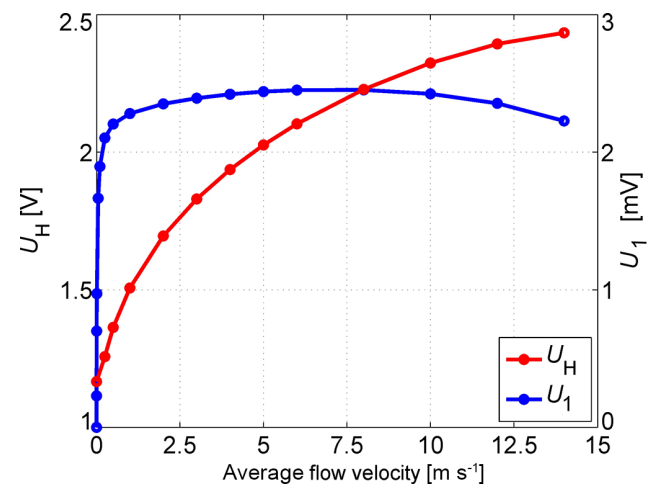

Figure 7. Simulation results (calorimetric approach) of the heater voltage $U_{\mathrm{H}}$ as well as the voltage $U_{1}$ vs. the average flow velocity for the operating mode with constant $U_{2}$ (corresponding to $T_{\mathrm{I}, \text { mean }}-T_{\mathrm{O} \text {, mean }}=4 K$ ).

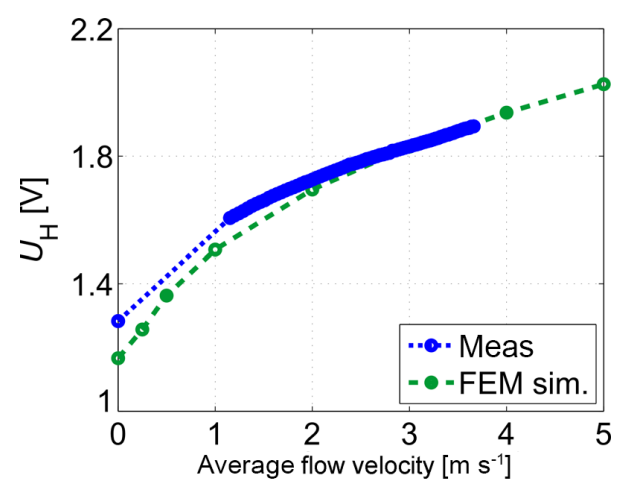

Figure 8. Simulation and measurement results (calorimetric approach) of the heater voltage $U_{\mathrm{H}}$ as a function of the average flow velocity in quasi-constant temperature mode.

ferent sensor designs, which differ in the gap width between the copper leads. The gap widths for designs 1,2 , and 3 amount to 100,200 , and $300 \mu \mathrm{m}$, respectively. With increasing the gap width, the heater voltage increases too in order to maintain the same constant temperature difference. This results in a higher sensitivity (slope of the output characteristic) for the sensors with larger gap width. This difference between the heater voltage of design 1 as a reference and designs 2 and 3 amounts to 13 and $25.7 \%$ at high velocities, respectively.

Figure 10 shows another comparison of output characteristics of sensor designs where perforations, in terms of drilled holes through the transducer, are inserted between the copper leads. For all three designs, the gap between the copper leads is $300 \mu \mathrm{m}$. Design 3 does not have any perforations; design 4 features hole diameters of 100 and $300 \mu \mathrm{m}$ spacing between the holes. In design 5, the spacing is reduced to $100 \mu \mathrm{m}$ with the same hole diameter as in design 4 . The holes decrease the parasitic heat conduction through the substrate. Therefore, the heater voltage decreases. 
Table 2. Mean sensitivity of the investigated designs in the range from 1 to $3.6 \mathrm{~m} \mathrm{~s}^{-1}$.

\begin{tabular}{lrrrrrrrrr}
\hline Design number & 1 & 2 & 3 & 4 & 5 & 6 & 7 & 8 & 9 \\
\hline Sensitivity in $\mathrm{mV} / \mathrm{m} \mathrm{s}^{-1}$ & 117 & 183 & 247 & 246 & 194 & 220 & 213 & 212 & 177 \\
\hline
\end{tabular}

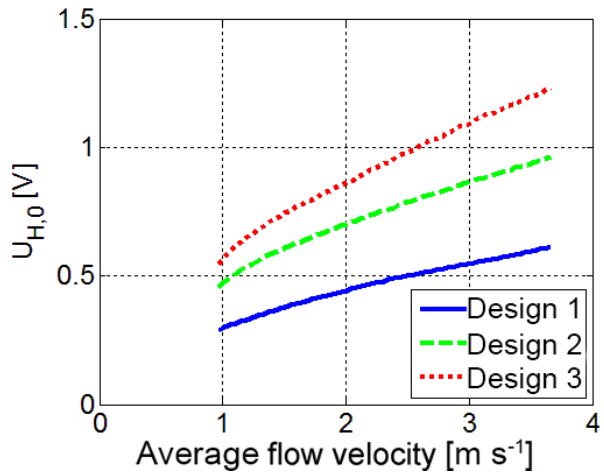

Figure 9. Comparison of the output characteristic of three different transducer designs (calorimetric approach) where the gap between the copper leads was varied. The gap widths for designs 1-3 amount to 100,200 , and $300 \mu \mathrm{m}$, respectively.

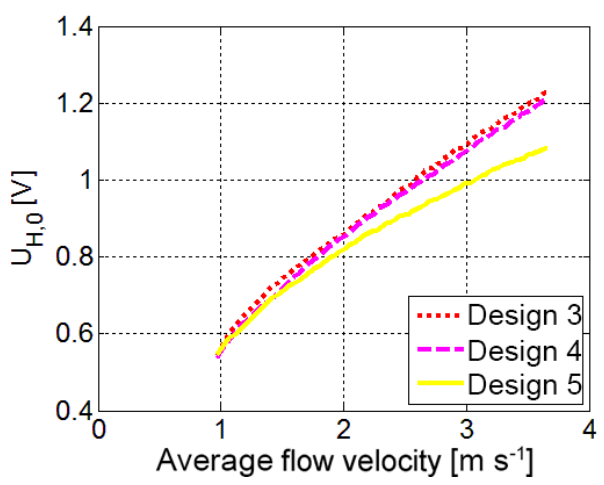

Figure 10. Comparison of the output characteristic of three different transducer designs (calorimetric approach) where perforations between the copper leads were added. Design 3 does not have any perforations; design 4 exhibits hole diameters of $100 \mu \mathrm{m}$ and $300 \mu \mathrm{m}$ spacing between the holes. In design 5 , the spacing is reduced to $100 \mu \mathrm{m}$ with the same hole diameter as in design 4.

In Fig. 11 the comparison of output characteristics of sensor designs featuring different wing widths is depicted. The wing width for designs 4,7 , and 9 amounts to $0.2,4.2$, and $8.86 \mathrm{~mm}$, respectively. The larger wing width decreases the heater voltage, and, hence, the sensor sensitivity. However, wide PCB stripes are less prone to fluttering and thus somewhat easier to integrate in the flow channel.

Table 2 gives an overview of the mean sensitivity of the individual designs in the flow range between 1 and $3.6 \mathrm{~m} \mathrm{~s}^{-1}$. Design 3 and 4 have the highest sensitivity, but they will also reach thermal saturation faster.

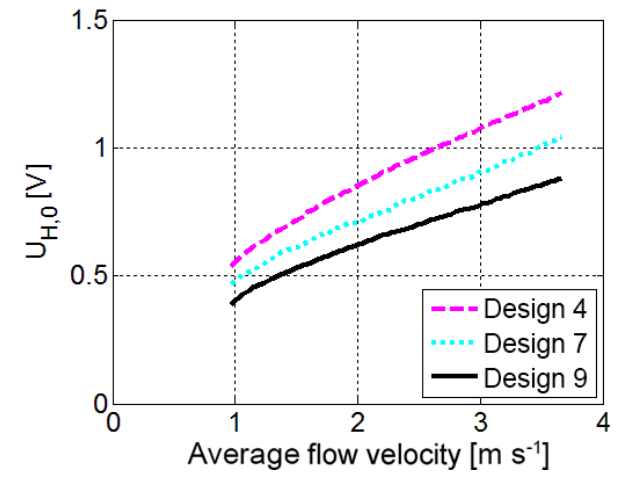

Figure 11. Comparison of the output characteristic of three different transducer designs (calorimetric approach) where the wing width was varied. The wing widths for designs 4,7 , and 9 amount to $0.2,4.2$, and $8.86 \mathrm{~mm}$, respectively.

\section{Conclusion}

A development of flow sensors for heating, ventilating, and air conditioning is presented in this paper. The aim was to use standard, low-cost and highly efficient technologies such as a printed circuit board to measure flow velocity over the whole cross section. The first approach was based on the hot-film transduction principle. A thin copper film was laminated on a flexible FR-4 substrate ( $100 \mu \mathrm{m}$ thickness). The characterization of the transducer revealed three major drawbacks: the saturation of the output characteristic, its temperature dependence, and no possibility to detect the direction of the flow. Therefore, the sensor design was revised by adding four temperature sensors arranged symmetrically around the heater. An electronic controller adjusts the heater voltage, keeping the mean temperature difference between the central and peripheral areas of the PCB constant. In this operating mode, the output characteristic is strictly monotonic over the whole desired flow range and does not depend on fluid temperature. Additionally, the flow direction can also be detected. Moreover, based on comprehensive FEM simulations, several transducer layouts were designed and produced. These different layouts were measured and compared with each other in order to optimise the flow sensor for HVAC systems. The influence of the gap width between the copper leads on the course of output characteristic was investigated. Moreover, the variation of the PCB stripe width, and, especially, the distance between the sensor edge and the copper leads was also considered. By increasing the gap (between the copper leads), the heater voltage also increases. Especially 
at higher flow velocities a $200 \mu \mathrm{m}$ increased gap yields to a $26 \%$ higher heater voltage. Conversely, decreasing the gap will lead to a lesser heater voltage. The minimal gap between the copper leads is $300 \mu \mathrm{m}$ when adding perforations with a $100 \mu \mathrm{m}$ hole diameter. Applying these perforations will decrease the heater voltage, because the parasitic heat conduction through the substrate is reduced. Unfortunately, perforations can only be inserted at a gap of $300 \mu \mathrm{m}$. Therefore, the minimal benefit from inserting perforations is overshadowed by the drawback of the increased gap. However, the producer may be able to insert perforations at smaller gaps in a cost-effective way in further developed designs. By enlarging the wing, the heater voltage will decrease because of a better mechanical robustness and a better developed thermal boundary layer (Schlichting and Gersten, 2006). In summary, to design a sensor for HVAC systems, the geometrical and physical parameters like maximum flow velocity, channel width, and fluid conditions have to be identified at first. Afterwards, the transducer layout can be designed, whereas FEM simulations help to estimate the output characteristic of the deduced layout. Therefore, the sensor can be applied in various HVAC systems and only the transducer layout has to be changed which is simple and cost effective with PCB technology. Moreover, a defect transducer can easily be replaced. This work showed that flow sensors based on printed circuit board technology are feasible for HVAC systems. Future work will focus on two main topics. First, the development of the controller circuit and its optimization. Here, an analog controller can be replaced by alternative circuits such as the Sigma-Delta-Modulator (Cerimovic et al., 2009). Its quasi digital output facilitates the connection to a network node as a second goal. The second one deals with the fusion of the transducer, the electronics, and the network node to one complete system adapted for HVAC applications.

Acknowledgements. This work has been financially supported by the Austrian Research Promotion Agency (FFG, research grant 834175). The Center for Integrated Sensor Systems gratefully acknowledges partial financial support by the European Regional Development Fund (EFRE) and the province of Lower Austria.

Edited by: S. Zimmermann

Reviewed by: two anonymous referees

\section{References}

Cerimovic, S., Talic, A., Beigelbeck, R., Sauter, T., Kohl, F., Schalko, J., and Keplinger, F.: A Novel calorimetric flow sensor implementation based on thermal sigma-delta modulation, IEEE Sensors, 1923-1926, doi:10.1109/ICSENS.2009.5398360, 2009.

Cerimovic, S., Talic, A., Beigelbeck, R., Antlinger, H., Sauter, T., Nicolics, J., Jakoby, B., and Keplinger, F.: Bidirectional micromachined flow sensor featuring a hot film made of amorphous germanium, Measurement Science and Technology, 24, 084002, doi:10.1088/0957-0233/24/8/084002, 2013.
Chua, B. and Pak, J. J.: Miniaturized corona flow sensor operating in drift mobility increment mode for low flow velocity measurement, Sensors and Actuators A: Physical, 224, 65-71, doi:10.1016/j.sna.2015.01.022, 2015.

Cruz, S., Viana, J., Dias, D., and Rocha, L.: Pressure sensing platform for health monitoring, IEEE International Symposium on Medical Measurements and Applications (MeMeA), 1-5, doi:10.1109/MeMeA.2014.6860131, 2014.

Cubukcu, A. S., Romero, D. F. R., and Urban, G. A.: A dynamic thermal flow sensor for simultaneous measurement of thermal conductivity and flow velocity of gases, Sensors and Actuators A: Physical, 208, 73-87, doi:10.1016/j.sna.2013.12.007, 2014.

Fitzner, K.: Raumklimatechnik, vol. 2, Springer, 16. edn., ISBN-13: 978-3-540-57011-0, 2008.

Glatzl, T., Kohl, F., Hortschitz, W., and Sauter, T.: Concept of a thermal flow sensor integration on circuit board level, Emerging Technologies \& Factory Automation (ETFA), 2013 IEEE 18th Conference on, 1-4, available at: http://ieeexplore.ieee.org/xpls/ absall.jsp?arnumber $=6648116,2013$.

Glatzl, T., Steiner, H., Kohl, F., Sauter, T., and Keplinger, F.: Characterization and optimization of a thermal flow sensor on circuit board level, 2014 IEEE Emerging Technology and Factory Automation (ETFA), 1-7, doi:10.1109/ETFA.2014.7005101, 2014.

Glatzl, T., Cerimovic, S., Steiner, H., Talic, A., Beigelbeck, R., Jachimowicz, A., Sauter, T., and Keplinger, F.: Development of Flow Sensors Realized with Printed Circuit Board Technology for Air Conditioning Systems, Measurement Fair SENSOR+TEST, available at: http://www.researchgate.net/profile/Harald_Steiner/publication/ 280527708_Development_of_Flow_Sensors_Realized_with_ Printed_Circuit_Board_Technology_for_Air_Conditioning_ Systems/links/55b7671508aed621de045ef4.pdf, 2015.

Grimes, C. A., Dickey, E. C., and Pishko, M. V.: Encyclopedia of Sensors, vol. 10, 203-217, ASP, 2006.

Ju, P.-Y., Tsai, C.-H., Fu, L.-M., and Lin, C.-H.: Microfluidic flow meter and viscometer utilizing flow-induced vibration on an optic fiber cantilever, in: Solid-State Sensors, Actuators and Microsystems Conference (TRANSDUCERS), 16th International, 1428-1431, IEEE, 5-9 June 2011.

Kaanta, B. C., Chen, H., Lambertus, G., Steinecker, W. H., Zhdaneev, O., and Zhang, X.: High sensitivity micro-thermal conductivity detector for gas chromatography, in: Micro Electro Mechanical Systems, 2009. MEMS 2009. IEEE 22nd International Conference on, 264-267, IEEE, 25-29 January 2009.

Kohl, F., Fasching, R., Keplinger, F., Chabicovsky, R., Jachimowicz, A., and Urban, G.: Development of miniaturized semiconductor flow sensors, Measurement, 33, 109-119, doi:10.1016/S0263-2241(02)00058-1, 2003.

Kuo, J. T. W., Yu, L., and Meng, E.: Micromachined Thermal Flow Sensors - A Review, Micromachines, 3, 550-573, doi:10.3390/mi3030550, 2012.

Leonard, W. F. and Yu, H.-Y.: Thermoelectric power of thin copper films, J. Appl. Phys., 44, 5320-5323, doi:10.1063/1.1662150, 1973.

Loefdahl, L. and Gad-el Hak, M.: MEMS-based pressure and shear stress sensors for turbulent flows, Meas. Sci. Technol., 10, 665, doi:10.1088/0957-0233/10/8/302, 1999.

Makinwa, K. A. A. and Huijsing, J. H.: A wind sensor with an integrated low-offset instrumentation amplifier, in: Electronics, Cir- 
cuits and Systems, ICECS, The 8th IEEE International Conference on, vol. 3, 1505-1508, IEEE, 2- September 2001.

Nguyen, N. T.: Micromachined flow sensors - a review, Flow measurement and Instrumentation, 8, 7-16, 1997.

Nguyen, S. D., Paprotny, I., Wright, P. K., and White, R. M.: MEMS capacitive flow sensor for natural gas pipelines, Sensors and Actuators A: Physical, doi:10.1016/j.sna.2014.10.013, 2014.

Nojdelov, R. and Nihtianov, S.: Capacitive-Sensor Interface With High Accuracy and Stability, IEEE T. Instrum. Meas., 58, 16331639, doi:10.1109/TIM.2009.2012957, 2009.

Perez-Lombard, L., Ortiz, J., and Pout, C.: A review on buildings energy consumption information, Energ. Buildings, 40, 394-398, doi:10.1016/j.enbuild.2007.03.007, 2008.

Prijic, A., Vracar, L., Vuckovic, D., Milic, D., and Prijic, Z.: Thermal Energy Harvesting Wireless Sensor Node in Aluminum Core PCB Technology, IEEE Sensors Journal, 15, 337-345, doi:10.1109/JSEN.2014.2343932, 2015.

Que, R., Zhu, R., Wei, Q., and Cao, Z.: A flexible integrated micromachined hot-film sensor array for measuring surface flow vector, in: Solid-State Sensors, Actuators and Microsystems Conference (TRANSDUCERS), 2011 16th International, 108-111, doi:10.1109/TRANSDUCERS.2011.5969149, 5-9 June 2011.

Reyes Romero, D. F., Kogan, K., Cubukcu, A. S., and Urban, G. A.: Simultaneous flow and thermal conductivity measurement of gases utilizing a calorimetric flow sensor, Sensors and Actuators A: Physical, 203, 225-233, doi:10.1016/j.sna.2013.08.025, 2013.
Saremi, S., Alyari, A., Feili, D., and Seidel, H.: A MEMSbased hot-film thermal anemometer with wide dynamic measurement range, in: 2014 IEEE SENSORS, 420-423, doi:10.1109/ICSENS.2014.6985024, 2014.

Sauter, T., Glatzl, T., Kohl, F., Steiner, H., and Talic, A.: Thermal flow sensors based on printed circuit board technology, in: Quality Electronic Design (ISQED), 15th International Symposium on, 748-753, IEEE, 3-5 March 2014.

Schlichting, H. and Gersten, K.: Grenzschicht-theorie, SpringerVerlag, ISBN-13: 978-3-540-23004-5, 2006.

Yu, B., Gan, Z., Cao, S., Xu, J., and Liu, S.: A micro channel integrated gas flow sensor for high sensitivity, in: Thermal and Thermomechanical Phenomena in Electronic Systems, ITHERM 2008, 11th Intersociety Conference on, 215-220, IEEE, 2831 May 2008.

Zhu, R., Liu, P., Liu, X., Zhang, F., and Zhou, Z.: A Low-Cost Flexible Hot-Film Sensor System for Flow Sensing and its Application to Aircraft, in: IEEE 22nd International Conference on Micro Electro Mechanical Systems, 2009, MEMS 2009, 527-530, doi:10.1109/MEMSYS.2009.4805435, 26-29 January 2009. 